\title{
Induction of Apoptosis in Cultured Human Stomach Cancer Cells by Potato Anthocyanins and Its Inhibitory Effects on Growth of Stomach Cancer in Mice
}

\author{
Kazuya Hayashi $^{1 *}$, Hiroshige Hibasami ${ }^{2}$, Tomoko Murakami ${ }^{1}$, Norihiko Terahara ${ }^{3}$, Motoyuki Mori ${ }^{4}$ and \\ Akio Tsukui ${ }^{1}$ \\ ${ }^{l}$ Tokyo Kasei Gakuin Junior College, 22 Sanbancho, Chiyoda-ku, Tokyo 102-8341, Japan \\ ${ }^{2}$ Faculty of Medicine, Mie University, 2-174 Edobashi, Tsu-city, Mie 514-8507, Japan \\ ${ }^{3}$ Department of Food Science for Health, Faculty of Health and Nutrition, Minami-Kyushu University, 5-1-2 Kirishima, Miyazaki, \\ Miyazaki 880-0032, Japan \\ ${ }^{4}$ National Agricultural Research Center for Hokkaido Region Research Team for Potato Production and Protection, Memuro-cho, \\ Hokkaido 082-0071, Japan
}

Received May 7, 2005; Accepted January 22, 2006

\begin{abstract}
Anthocyanins prepared from colored potatoes induce apoptosis in cultured human stomach cancer KATO III cells. Morphological change indicating apoptotic bodies and DNA fragmentations were observed in cells treated with potato anthocyanins.

Feeding with steamed red potato alone and purple potato alone suppressed by $46.2 \%$ and $38.5 \%$, respectively, the growth of mouse stomach cancer as compared with the feeding with Irish Cobbler. Feeding with a $1 \%$ solution of red or purple potato anthocyanin with standard food suppressed by $47.6 \%$ and $38.1 \%$, respectively, growth of mouse stomach cancer. So, eating of potatoes containing large amounts of anthocyanin to maintain the presence of potato anthocyanin in the stomach is recommended as a possible method for protecting humans from stomach cancer.
\end{abstract}

Keywords: anthocyanin-containing potatoes, stomach cancer KATO III cells, DNA fragmentation, apoptosis, antitumor activity

\section{Introduction}

The anthocyanin-containing red-fleshed potato 'Inca Red' (red potato) and purple-fleshed potato 'Inca Purple' (purple potato) were bred from hybrid seedlings between cultivars of Solanum tuberosum ssp. tuberosum and $S$. tuberosum ssp. andigena (Hayashi et al., 1997; Naito et al., 1998; Mori et al., 2000). The red- and purple-potato anthocyanins have strong antioxidative activities (Ishii et al., 1996b) and anti-influenza virus activities (Hayashi et al., 2003).

In recent years, antioxidative polyphenols of several plants such as green tea catechins (Hibasami et al., 1998a, Saeki et al., 1999), black tea theaflavins (Hibasami et al., 1998b), adzuki extracts polyphenols (Itoh et al., 2002), kinjiso polyphenols (Hayashi et al., 2002), bitter gourd polyphenols (Etoh et al., 2002) and anthocyanins (Katsuzaki et al., 2003, Katsube et al., 2003, Hou et al., 2003, Scovassi et al., 2004, Fimognari et al., 2004, Hyun et al., 2004, Heo et al., 2005, Chang et al., 2005) have all been reported to induce apoptosis.

As a part of their action on neoplastic cells, some antitumor compounds induce apoptosis (programmed cell death) (Jiang et al., 1995; Lotan, 1995; Piazza et al., 1995).

* To whom correspondence should be addressed.

Kazu-hayashi@mtc.biglobe.ne.jp
Apoptosis may be a primary mechanism of antineoplastic agent (Hickman, 1995). Apoptosis is an orchestrated series of events through which the cell precipitates its own death. The stages of apoptosis include cell shrinkage, chromatin condensation, nuclear segmentation and internucleasomal fragmentation of DNA, resulting in the generation of apoptotic bodies (Kerr et al., 1972).

In this study, we report that the anthocyanins present in red potato and purple potato induce apoptosis in human stomach cancer cell line and that feeding with these anthocyanins suppressed grow th of stomach cancer in mice.

\section{Materials and Methods}

Materials Anthocyanin-containing red-fleshed potato 'Inca Red' and purple-fleshed potato 'Inca Purple' were cultivated in the fields of the Potato Breeding Laboratory, Hokkaido National Agricultural Experiment Station (Memuro, Kasai-Gun, Hokkaido). RPMI 1640 medium, Eagle's minimal essential medium and heat-inactivated fetal bovine serum were obtained from Gibco Laboratories, Grand Island, NY USA. Lymphocyte separation medium (LSM) was purchased from ICN Biochemicals Inc., Aurora, $\mathrm{OH}$, USA.

Anthocyanin preparation The red or purple potatoes were sliced to a thickness of $1 \mathrm{~mm}$ by using a slicer and 
were extracted with $3 \%$ trifluoroacetic acid (TFA)aqueous solution overnight at $4^{\circ} \mathrm{C}$. After filtration with paper filter No.3 (Advantec Toyo, Tokyo), the pigment extract was passed through an Amberlite XAD-7 (Organo, Tokyo) column (30 mm I.D. $\times 450 \mathrm{~mm}$ ). After washing the column with water, the adsorbed pigments containing anthocyanins were eluted with $70 \%$ ethanol. The pigment eluate was dried under vacuum at $40^{\circ} \mathrm{C}$. The crude pigment dissolved in 99.5\% ethanol was filtered with paper filter No. 5c (Advantec Toyo, Tokyo) and concentrated under vacuum at $40^{\circ} \mathrm{C}$. The concentrated pigment eluate was freeze-dried to obtain red- or purple-potato anthocyanin powders (potato anthocyanin). (Hayashi et al., 1997)

Cell culture Human stomach cancer KATO III cells were originally provided by the American Type Culture Collection (ATCC) and given by Health Science Research Resources Bank (HSRRB), Osaka, Japan. Human stomach cancer KATO III cells were grown in 45\% RPMI 1640 medium with $45 \%$ Eagle's minimal essential medium and $10 \%$ heat-inactivated fetal bovine serum containing penicillin $\mathrm{G}(50 \mathrm{IU} / \mathrm{ml})$ and streptomycin $(50 \mu \mathrm{g} / \mathrm{ml})$ at $37^{\circ} \mathrm{C}$ in a humidified 95\% air-5\% $\quad \mathrm{CO}_{2}$ atmosphere and passaged every 4 days. Mycoplasma testing was routinely negative.

Microscopic observation of morphological change of KATO III cells The exponentially multiplying human stomach cancer KATO III cells were plated at an initial density of $3-4 \times 10^{5}$ cells $/ \mathrm{ml}$. After cultivation for 3 days in the presence of a vehicle or the potato anthocyanin, the morphology of the cells was examined by a epifluorescence microscope with a cooled CCD camera digital imaging system and Fuji pictrography 3000 as described by Okumura et al. (1995).

For preparation of normal human lymphocyte cell, $3 \mathrm{ml}$ of lymphocyte separation medium (LSM) was aseptically transferred to a centrifuge tube and diluted blood (heparinized blood: physiological saline $=1: 1$ ) was layered over the LSM in the tube. The tube was centrifuged at $400 \mathrm{x} \mathrm{g}$ at room temperature for $20 \mathrm{~min}$. The top layer of clear plasma was removed, and the lymphocyte layer was transferred to a new centrifuge tube. An equal volume of $0.01 \mathrm{M}$ phosphate-buffered saline ( $\mathrm{pH} 7.5$ ) was added to the lymphocyte layer in the tube and centrifuged for 10 min at room temperature at $260 \mathrm{x}$ g. After centrifugation, the precipitated lymphocyte was washed with $0.01 \mathrm{M}$ phosphate-buffered saline $(\mathrm{pH}$ 7.5), and suspended in RPMI-1640 medium containing 10\% FCS and 2\% phytohemaglutinin-M (Gibco Labo-ratories, Grand Island, Ny, USA). The obtained normal human lymphocyte cells were cultivated in the presence of red- or purple-potato anthocyanin.

Assay for DNA fragmentation Exponentially growing cells were plated at an initial density of $3-4 \times 10^{5}$ cells/ $\mathrm{ml}$ in the culture flask. After cultivation in the presence of a vehicle, red or purple potato anthocyanins for 3 days, the cells were pelleted by slow centrifugation for $5 \mathrm{~min}$. DNA was isolated from the cell pellets using a previously described method (Mori et al., 1997). Equivalent amounts of DNA $(2 \mu \mathrm{g})$ were put into the well of $2 \%$ agarose gel and electrophoresed in $40 \mathrm{mM}$ Tris-acetic acid ( $\mathrm{pH} 7.5)$ containing $2 \mathrm{mM}$ EDTA.

Animals' experiment Benzo $(\alpha)$ pyrene-induced tumorigenesis in the forestomach of $\mathrm{A} / \mathrm{J}$ mice was performed according to a slight modification of the procedure described by Wattenberg (1987). Female A/J mice, 6 -week old (body weight: $25 \mathrm{~g}$ ), were purchased from Japan SLC. Ltd. (Hamamatsu, Shizuoka, Japan). The mice were housed in an air-conditioned room with a $12 \mathrm{~h}$ light/dark cycle (8: 00-20: 00 light), a temperature range of $22-23^{\circ} \mathrm{C}$ and a relative humidity of $25 \%$ throughout the experimental period and fed MF pellets (SLC. Ltd., Hamamatsu, Japan).

In the first animal experiment (Table 2), steamed tubers of Irish Cobbler (common potato), purple potato and red potato were fed to mice, to which benzo $(\alpha)$ pyrene $(1.5 \mathrm{mg}$ / $100 \mu \mathrm{L}$ of corn oil) was administered by gastric intubation once a week for periods of initial 4 weeks.

In the second animal experiment (Table 3), water (a vehicle), $1 \%$ solution of red- or purple-potato anthocyanin in water were given to those mice initiated carcinogenesis and fed MF pellet as described above.

The mice were sacrificed after 5 months to evaluate the number of tumors and the weights of the tumors generated in the stomach.

Coefficient of repression of growth of stomach cancer by ingestion of steamed potatoes $(\%)=\{1-$ [Weight $(\mathrm{g})$ of tumors of stomach cancer in mouse eating potatoes containing anthocyanin]/[Weight(g) of tumors of stomach cancer in mouse eating Irish Cobbler $]\} \times 100$.

Coefficient of repression of growth of stomach cancer by ingestion of potato anthocyanin solutions $(\%)=\{1-$

Table 1. Effect of red potato anthocyanin on the growth of KATO III cells.

\begin{tabular}{lcc}
\hline Compound & Concentration $(\mathrm{mg} / \mathrm{ml})$ & Inhibition \\
\hline Control $(50 \%$ ethanol) & 0 & 0 \\
Red potato anthocyanin & 0.5 & 22 \\
& 1.0 & 36 \\
& 2.0 & 53 \\
& 2.5 & 56 \\
\hline
\end{tabular}

KATO III cells were exposed to red potato anthocyanin at the indicated concentrations for 3 days before the cell number was estimated. 

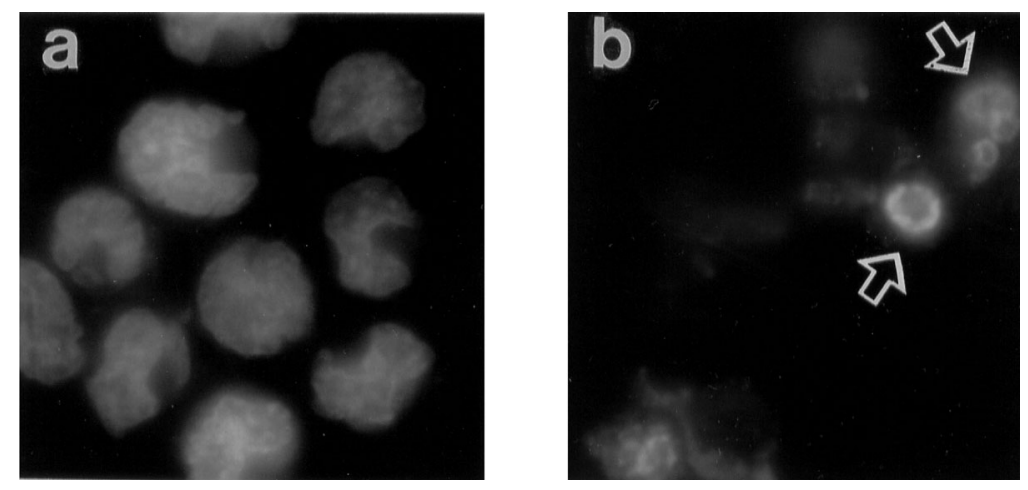

Fig. 1. Morphological changes of KATO III cells.

(a) non-treated cells, (b) KATO III cells treated with $2.5 \mathrm{mg} / \mathrm{ml}$ red potato anthocyanin. These cells were cultivated with red potato anthocyanin for 3 days and then observed under an epifluorescence microscope equipped with a cooled CCD camera (Phometrics, PXL 1400) digital imaging system and Fuji Pictography 3000. Arrows indicate apoptotic bodies.

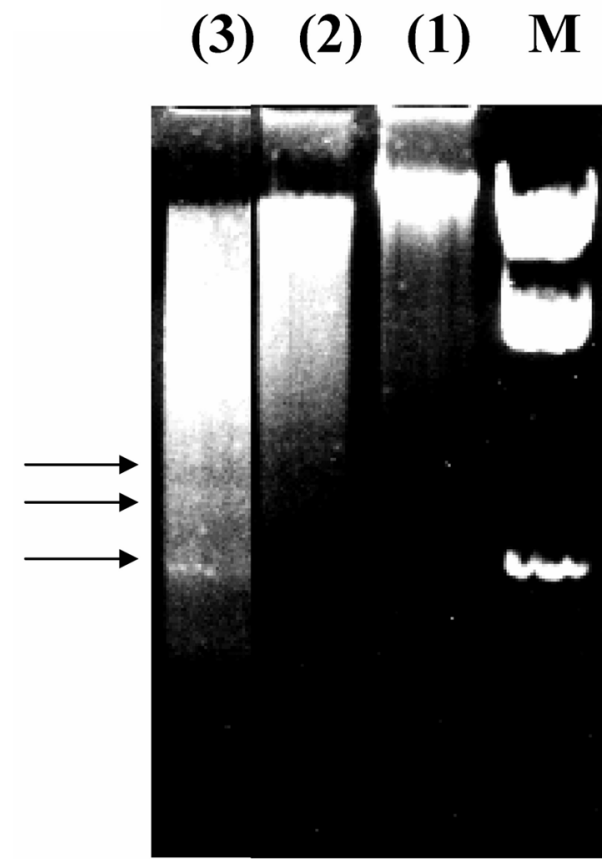

Fig. 2. Dose-dependency of induction of apoptosis by potato anthocyanins in KATO III cells.

The cells were cultivated in the absence (lane 1) or presence of purple potato anthocyanin (lane $2,2.5 \mathrm{mg} / \mathrm{ml}$ ), red potato anthocyanin (lane $3,2.5 \mathrm{mg} / \mathrm{ml}$ ), for 3 days. After the isolation of DNA from potato anthocyanins-treated cells, equivalent amounts of DNA $(2 \mu \mathrm{g})$ were loaded into wells of $2 \%$ agarose gel. and electrophoresed in $40 \mathrm{mM}$ Tris-acetic acid, pH 7.5 containing $2 \mathrm{mM}$ EDTA. Arrows indicate DNA ladders.

$\mathrm{M}: \lambda$ DNA digested with Hind III

[Weight (g) of tumors of stomach cancer in mouse drinking $1 \%$ potato anthocyanin solutions]/[Weight (g) of tumors of stomach cancer in mouse drinking water]\} $\times 100$.

Statistical analysis Results are expressed as mean \pm SD. The level of significance in the difference between groups was calculated by the student's $t$-test. The difference between means were considered to be significant at $p$
$<0.01$ or $p<0.05$ by the student's t-test.

\section{Results and Discussion}

The proliferation of KATO III cells was inhibited as the concentration of the red potato anthocyanin was increased (Table 1). The significant growth-inhibitory activity of the potato anthocyanin led us to investigate whether part of the antitumor effect was a result of apoptosis induction. Morphological change indicating apoptotic bodies and fragmentation of genomic DNA into oligonucleosomal-sized fragments are characteristics of the occurrence of apoptosis. The morphology of the treated KATO III cells shows apoptotic bodies after 3 days of treatment with the red potato anthocyanin (Fig. 1).

Figure 2 shows the amount of oligonucleosomal-sized fragments in the KATO III cells treated with $2.5 \mathrm{mg} / \mathrm{ml}$ of the crude red- potato or purple-potato anthocyanin.

Table 2 summarizes the preventive effects of the feeding of steamed tubers of purple potato or red potato on benzo $(\alpha)$ pyrene-induced tumorigenesis in the forestomach of the mice. The number and weight of the tumors were evaluated at 5 months after the final administration of benzo $(\alpha)$ pyrene. Both the estimated values were significantly lower in the group fed steamed colored potatoes than in the group fed steamed common potato (Irish Cobbler). Red potato and purple potato suppressed by $46.2 \%$ and $38.5 \%$, respectively, the weight of the tumors as compared with Irish Cobbler. It was considered that the growth of stomach cancer was repressed when the red or purple potato in a cooked state were orally fed (Table 2).

Similar effects were observed in the mice given the $1 \%$ solution of potato anthocyanins (Table 3). Purple-potato anthocyanin and red-potato anthocyanin suppressed by $38.1 \%$ and $47.6 \%$, respectively, the weight of stomach tumors as compared with that of the control mice which were fed with water only.

These data indicate that anthocyanin contained in the colored potatoes induce apoptosis in cancer cells and suppress proliferation of the mouse stomach cancer.

This finding supports the possibility that potato 
Table 2. Repressible effect of steamed potatoes on growth of stomach cancer in mice.

\begin{tabular}{llccc}
\hline Sample & $\begin{array}{l}\text { Number of } \\
\text { tumors / Mouse }\end{array}$ & $\begin{array}{c}\text { Weight of } \\
\text { tumors }(\mathrm{g}) / \text { Mouse }\end{array}$ & $\begin{array}{c}\text { Coefficient of } \\
\text { Repression (\%) }\end{array}$ \\
\hline Irish Cobbler & $4.9 \pm 1.1$ & $0.13 \pm 0.04$ & - \\
Red potato & $3.3 \pm 1.1$ & $0.07 \pm 0.03$ & 46.2 \\
Purple potato & $4.1 \pm 0.9$ & $0.08 \pm 0.02$ & 38.5 \\
\hline
\end{tabular}

Steamed potatoes were fed orally to 5 mice ad libitum.

Coefficient of repressible effect on carcinogenesis of stomach cancer in mouse $(\%)=\{1-$

[weight of tumors (g) of stomach cancer in mouse having ingested red or purple potato] / [weight of tumors $(\mathrm{g})$ of stomach cancer in mouse having ingested Irish Cobbler]

$\times 100$

Table 3. Repressible effect of potato anthocyanins on growth of stomach cancer in mice.

\begin{tabular}{lccc}
\hline Sample & $\begin{array}{c}\text { Number of } \\
\text { tumors / Mouse }\end{array}$ & $\begin{array}{c}\text { Weight of } \\
\text { tumors (g) / Mouse }\end{array}$ & $\begin{array}{c}\text { Coefficient of } \\
\text { Repression (\%) }\end{array}$ \\
\hline Control (Water) & $9.6 \pm 1.0$ & $0.21 \pm 0.02$ & - \\
Red potato anthocyanin (1\%) & $4.8 \pm 0.5$ & $0.11 \pm 0.01$ & 47.6 \\
Purple potato anthocyanin (1\%) & $5.2 \pm 0.5$ & $0.13 \pm 0.01$ & 38.1 \\
\hline
\end{tabular}

An $1 \%$ solution of red or purple potato anthocyanin in water was adoministered available ad libitum, with MF pellet (SLC. Ltd., Hamamatsu, Shizuoka, Japan).

Coefficient of repressible effect on the growth of stomach cancer in mouse $(\%)=\{1-$

[weight of tumors $(\mathrm{g})$ of stomach cancer in mouse having red or purple potato anthocyanin

$(1 \%)] /$ weight of tumors $(\mathrm{g})$ of stomach cancer in mouse having ingested water $\} \times 100$

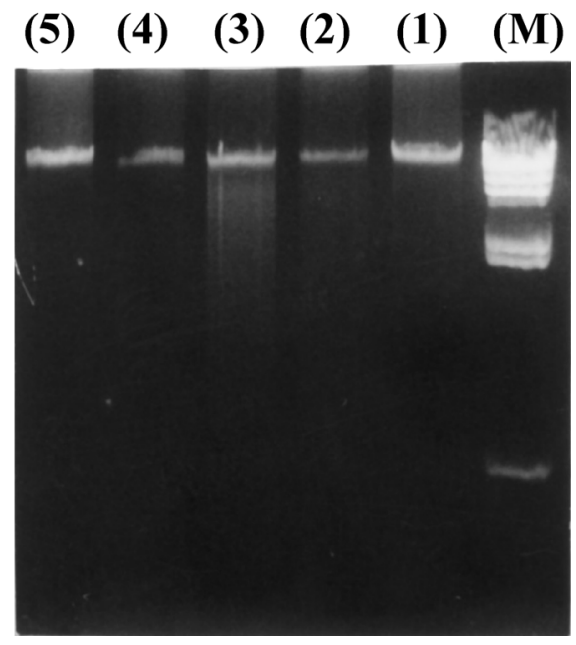

Fig. 3. Effect of the potato anthocyanins on apoptotic induction in human normal lymphocyte cells.

The cells were cultivated in the presence of a vehicle $(50 \%$ ethanol, lane 1), purple anthocyanin (lane 2, $2.5 \mathrm{mg} / \mathrm{ml}$ ), purple potato anthocyanin (lane $3,5.0 \mathrm{mg} / \mathrm{ml}$ ), red potato anthocyanin (lane $4,2.5 \mathrm{mg} / \mathrm{ml}$ ), red potato anthocyanin (lane $5,5.0 \mathrm{mg} / \mathrm{ml}$ ), for 3 days. After the isolation of DNA from the treated cells, equivalent amounts of DNA $(2 \mu \mathrm{g})$ were loaded into wells of $2 \%$ agarose gel and electrophoresed in $40 \mathrm{mM}$ Tris-acetic acid, $\mathrm{pH} 7.5$ containing $2 \mathrm{mM}$ EDTA.

$\mathrm{M}: \lambda$ DNA digested with Hind III anthocyanins are the main compounds having antitumor activity. About 10 types of pigment were contained in the purple- potato anthocyanin fraction and about eight types of pigment were contained in the red-potato anthocyanin fraction (Ishii et al., 1996; Hayashi et al., 1997; Naito et al., 1998). Further work is needed to clarify which substance exhibits cancer prevention.

In contrast, we have observed no induction of apoptosis by addition of $5.0 \mathrm{mg} / \mathrm{ml}$ of red- or purple-potato anthocyanin into normal lymphocytes prepared from healthy volunteers (Fig. 3).

As anthocyanins prepared from colored potatoes are used by mankind as food, we can them consume confidently and frequently in the same manner as ordinary food and drink. As these anthocyanins have no side effect, we can consume them continually as cancer-prevention food. Furthermore, as potato anthocyanins are naturally colored, those potato pigments impart an aesthetic visual effect on food and drink.

\section{References}

Etoh, S., Iwashita, K., Takei, T., Yamaki, K., Shinohara, K. and Kobori, M. (2002). Bitter gourd induces apoptosis in cancer cells lines. Nippon Shokuhin Kagaku Kougaku Kaishi, 49, 250-256 (in Japanese).

Chag, YC., Huang, HP., Hsu, JD., Yang, SF. and Wang, CJ. (2005). Hibiscus anthocyanins rich extract-induced apoptotic cell 
death in human promyelocytic leukemia cells. Toxical. Appl. Pharmacol., 205, 201-212.

Fimognari, C., Berti, F., Nusse, M., Cantelli-Forti, G. and Hrelia, P. (2004). Induction of apoptosis in two human leukemia cell lines as well as differentiation in human promyelocytic cells by cyanidin-3-O- $\beta$-glucopyranoside. Biochem. Pharmacol. 67, 20472056.

Hayashi, K., Suzuki, A., Tsukui, A., Takamatsu, N., Naito, K., Okada, T., Mori, M. and Umemura, Y. (1997). Characteristic anthocyanin, vitamin C, dietary fiber and sucrose contents of new types of colored potatoes. Nihon Kasei Gakkaishi, 48, 589596 (in Japanese).

Hayashi, K., Mori, M., Matutani, Y., Suzutani, T., Ogasawara, M,. Yoshida, I., Hosokawa, K., Tsukui, A. and Azuma, M. (2003) Anti influenza virus activity of a red-fleshed potato anthocyanin. Food Sci. Technol. Res., 9, 242-244.

Hayashi, M., Iwashita, K., Katsube, N., Yamaki, K. and Kobori, M. (2002). Kinjiso colored extract induce apoptosis in HL60 leukemia cells., Nippon Shokuhin Kagaku Kougaku Kaishi, 49, 519-526 (in Japanese).

Heo, HJ. and Lee, CY. (2005). Strawberry and its anthocyanins reduce oxidative stress-induced apoptosis in PC12 cells. J. Agric. Food Chem., 53, 1984-1989.

Hibasami, H., Komiya, T., Achiwa, Y., Ohnishi, K., Kojima, T., Nakanishi, K., Akashi, K. and Hara, Y. (1998a). Induction of apoptosis in human stomach cancer cells by green tea catechins. Oncol. Rep. 5, 527-529.

Hibasami, H., Komiya, T., Achiwa, Y., Ohnishi, K., Kojima, T., Nakanishi, K., Sugimoto, Y., Hasegawa. M., Akatsuka, R. and Hara, Y. (1998b). Black tea theaflavins induce programmed cell death in cultured human stomach cancer cells. Int. J. Mol. Med., 1, 725-727.

Hickman, JA (1992). Apoptosis induced by anticancer drugs. Cancer Metastasis Rev 11, 121-139.

Hou, DX., Ose, T., Lin, S., Harazoro, K., Imamura, I., Kubo, M., Uto, T., Terahara, N., Yoshimoto, M. and Fujii, M. (2003). Anthocyanidins induce apoptosis in human promyelocytic leukemia cells: structure-activity relationship and mechanisms involved. Int. J. Oncol., 23, 705-712.

Hyun, JW. and Chung, HS. (2004). Cyanidin and Malvidin from Oryza sativa cv. Heugjinjubyeo mediate cytotoxicity against human monocytic leukemia cells by arrest of $\mathrm{G}(2) / \mathrm{M}$ phase and induction of apoptosis. J. Agric. Food Chem., 52, 2213-2217.

Ishii, G., Mori, M., Umemura, Y., Takigawa, S. and Tawara, S. (1996 a). The structure of red and purple anthocyanins and their production in colored tuber flesh of diploid potatoes, Solanum tuberosum L., Nippon Shokuhin Kagaku Kougaku Kaishi, 43, 887-895 (in Japanese).

Ishii, G., Mori, M. and Umemura, Y. (1996a). Antioxidative activity and food chemical properties of anthocyanins from the colored tuber flesh of potatoes., Nippon Shokuhin Kagaku Kougaku Kaishi, 43, 962-966 (in Japanese).

Itoh, T., Itoh, Y., Mizutani, M., Fujishiro, Y., Komiya, T. and Hibasami, H. (2002). A hot water extract of adzuki induces apoptosis in cultured human stomach cancer cells, Nippon
Shokuhin Kagaku Kougaku Kaishi, 49, 339-344 (in Japanese).

Jiang, B., Li, DD. and Zhen, YS. (1995). Induction of apoptosis by enediyne antitumor antibiotic CI027 in HL-60 human promyelocytic Leukemia cells. Biochem. Biophys. Res. Commun., 208, 238-244.

Katsuzaki, H., Hibasami, H., Ohwaki, S., Ishikawa, K., Imai, K., Date, K., Kimura, Y. and Komiya, T. (2003). Cyanidin 3-O- $\beta$-Dglucoside isolated from skin of black Glycine max and other anthocyanins isolated from skin of red grape induce apoptosis in human lymphoid leukemia Molt 4B cells. Oncol. Rep., 10, 297-300.

Katsube, N., Iwashita, K., Tsushida, T., Yamaki, K. and Kobori, M. (2003). Induction of apoptosis in cancer cells by Bilberry (Vaccinium myrtillus) and the anthocyanins. J. Agric. Food Chemi., 51, 68-75.

Kerr, JF., Wyllie, AH. and Currie, AR. (1972). Apoptosis: a basic biological phenomenon with wide-ranging implications in tissue kinetics. Br. J. Cancer., 26, 239-257.

Lotan, R. (1995). Retinoids and apoptosis: implications for cancer chemoprevension and therapy. J. Natl. Cancer Inst., 87, 16551657.

Mori, K., Hibasami, H., Satoh, N., Sonoda, J., Yamasaki, T., Tajima, M., Uchida, A. and Nakashima, K. (1997). Induction of apoptotic cell death in three human osteosarcoma cell lines by a polyamine synthesis inhibitor, methylglyoxal bis (cyclopentylamidinohydrazone) (MGBCP). Anticancer Res., 17, 2390-2395.

Mori, M., Takada, A., Kobayashi, A., Tsuda, S. and Hayashi, K. (2000). Breeding for high anthocyanin potatoes. Pigments content of tetraploid selected line. Breeding Res. Tsukuba April 23, 127 (in Japanese).

Naito, K., Umemura, Y., Mori, M., Sumida, T., Okada, T., Takamatsu, N., Okawa, Y., Hayashi, K., Saito, N. and Honda, T. (1998). Acylated pelargonidin glycosides from a red potato. Phytochemistry, 47, 109-112

Okumura, K., Nogami, M., Taguchi, H., Hisamatsu, H. and Tanaka, K. (1995). The genes for the e-type HC3 and B-type HC5 subunits of human proteasome map to chromosomes $6 \mathrm{q} 27$ and $7 \mathrm{q} 1$ 2-pl3 by fluorescence in site hybridization. Genomics, 27, 377379.

Piazza, GA., Rahm, AL., Krutzsch, M., Sperl, G., Paranka, NS., Gross, PH., Brendel, K., Burt, RW., Alberts, DS. and Pamukcu, R. (1995). Antineoplastic drugs sulindac sulfide and sulfone inhibit cell growth by inducing apoptosis. Cancer Res., 55, 3110-3116.

Saeki, K., Sano, M., Miyase, T., Nakamura, Y., Hara, Y., Aoyagi, Y. and Isemura. (1999). Apoptosis-inducing activity of polyphenol compounds derived from tea catechins in human histiolytic lymphoma U937 cells., Biosci. Biotechol. Biochem., 63, 585-587.

Scovassi, AI., Stivala, LA. and Bianchi, L. (2004). Anthocyanins induce cell cycle perturbations and apoptosis in different human cell line. Carcinogenesis, 25, 1427-1433.

Wattenberg, LW. (1987). Inhibitory effects of benzyl isothiocyanate administered shortly before dimethylnitrosamine or benzo $(\alpha)$ pyrene on pulmonary and forestomach neoplasia in $\mathrm{A} / \mathrm{J}$ mice. Carcinogenesis (Lond)., 8, 1971-1973. 